\title{
The relationship between the speech perception and the degree of satisfaction among adult users of cochlear implants
}

\author{
Fernanda Soares Granço', Nayara Freitas Fernandes', Marina Morettin², Orozimbo Alves Costa Filho 3 , Maria Cecília Bevilacqua ${ }^{4}$. \\ 1) MSc Graduate student. Master's degree. Speech pathologist and audiologist. \\ 2) $\mathrm{PhD}$ in Science. Speech pathologist and audiologist. \\ 3) Full Professor, Professor in the Speech Therapy Course (Otolaryngologist) \\ 4) Full Professor, Speech Therapist and Audiologist, Speech Therapy Course (Speech Pathologist and Audiologist). \\ Institution: Bauru School of Dentistry, University of São Paulo. \\ Bauru / SP - Brazil \\ Mailing address: Fernanda Soares Granço - Al. Octávio Pinheiro Brisolla, 9-75 - Bauru / SP - Brazil - Zip code: $17012-901$ - Telephone: (+ 55 14) $3235-8246$-Fax: \\ (+ 55 14) 3234-3164 - E-mail: fergranco@ hotmail.com \\ Article received on October 4, 2012. Article accepted on December 25, 2012
}

\section{SUMMARY}

Introduction: In recent years, the benefits associated with the use of cochlear implants (CIs), especially with regard to speech perception, have proven to surpass those produced by the use of hearing aids, making CIs a highly efficient resource for patients with severe/profound hearing loss. However, few studies so far have assessed the satisfaction of adult users of CIs.

Objective: To analyze the relationship between the level of speech perception and degree of satisfaction of adult users of CI. Method: This was a prospective cross-sectional study conducted in the Audiological Research Center (CPA) of the Hospital of Craniofacial Anomalies, University of São Paulo (HRAC/USP), in Bauru, São Paulo, Brazil. A total of 12 users of CIs with prelingual or post-lingual hearing loss participated in this study. The following tools were used in the assessment: a questionnaire, "Satisfaction with Amplification in Daily Life" (SADL), culturally adapted to Brazilian Portuguese, as well as its relationship with the speech perception results; a speech perception test under quiet conditions; and the Hearing in Noise Test (HINT)Brazil under free field conditions.

Results: The participants in the study were on the whole satisfied with their devices, and the degree of satisfaction correlated positively with the ability to perceive monosyllabic words under quiet conditions. The satisfaction did not correlate with the level of speech perception in noisy environments.

Conclusion: Assessments of satisfaction may help professionals to predict what other factors, in addition to speech perception, may contribute to the satisfaction of CI users in order to reorganize the intervention process to improve the users' quality of life.

Keywords: Cochlear Implantation; Hearing Loss; Adult; Auditory Perception.

\section{INTRODUCTION}

The major adverse consequences of hearing impairment for an individual's social, emotional, cognitive, behavioral, and economic well-being and overall quality of life are well documented in the literature (17). Most patients with hearing impairments benefit from the use of hearing aids. However, these devices may not fully compensate for severe and/or profound hearing loss in which the damage to the auditory system is extensive (3). The use of cochlear implants (CIs) is indicated for both children and adults in such cases.

In recent years, the benefits conferred by the use of CIs, especially with regard to speech perception, have proven to surpass those produced by the use of hearing aids, making CIs a highly efficient resource for patients with severe/profound hearing loss. However, few studies so far have assessed the satisfaction of adult users of CIs.
Research on patients' perceptions of the health services that they receive has been a constant concern of researchers and professionals responsible for health care. The definition of satisfaction may vary in order to address different research objectives (e.g., to assess quality or to understand user perception) and different aspects of the service, from the institution's "amenities of care," such as the food, cleanliness, and comfort, to the technical quality of the services (6). Satisfaction reflects the perspective of the patient and thus depends not only on the performance of the CIbut also on the patient's perceptions and attitudes. Therefore, it is very important to know what factors are related to patients' satisfaction and how these factors influence patient perception in order to refine the objectives of rehabilitation in response to the patient's needs.

However, there is currently no questionnaire or inventory that was developed specifically to evaluate the satisfaction of CI users. In a study conducted by Ou, et al. (12) (2008), the Satisfaction with Amplification in Daily 
Life (SADL) questionnaire developed by Cox and Alexander (4) (1999), which assesses the satisfaction of users of hearing aids, was adapted for use in CI recipients and reportedly proved appropriate for this population. No study using this tool to evaluate the satisfaction of users of CIs has been conducted in Brazil.

Therefore, this study aimed to evaluate the degree of satisfaction of adult users of CIs and the relationship thereof with their levels of speech perception.

\section{Methods}

This was a prospective cross-sectional study conducted in the Audiological Research Center (CPA) of the Hospital of Craniofacial Anomalies, University of São Paulo (HRAC/USP), in Bauru, São Paulo, Brazil.

The project was approved by the Ethics Committee of HRAC/USP Bauru under case No. 249-2011-SVAPEPECEP on September 5, 2011. The individuals who participated in this study signed a consent form.

\section{Selection of participants}

This study comprised a sample of 12 adult users of CIs who were patients at the Audiological Research Center of the Hospital for Rehabilitation of Craniofacial Anomalies/ University of São Paulo (CPA, HRAC/USP), all of whom used CI models and technologies available in Brazil. The age of these patients ranged from 19 to 59 years and their durations of CI use from 1 to 15 years. All participants used their CIs daily for at least 8 hours a day.

All patients who visited for routine monitoring from April through July 2012 were invited to participate in the study, and the sample consisted of those who spontaneously agreed to enroll. The participants were invited from among patients who visited for routine monitoring from April through July 2012.

The inclusion criteria for this study were age e"18 years, use of unilateral CIs with or without the use of contralateral hearing aids, and systematic use of CIs. Individuals who had severe limitations in understanding and expression that interfered with their responding to the questionnaire and individuals who did not agree to participate were excluded from the study.

\section{Procedures}

To evaluate satisfaction, we culturally adapted the Satisfaction with Amplification in Daily Life (SADL) questionnaire to Brazilian Portuguese (11). For use in this study, the questionnaire was modified to exclude questions 7 and 14, which relate to the cost of CIs and therefore do not apply in Brazil (12).

A previously trained examiner administered the questionnaire and addressed any doubts expressed by the participants without interfering in any way with their answers.

This questionnaire has 4 subscales:

- Positive effects (questions 1, 3, 5, 6, 9, and 10): 6 items related to acoustic and psychological benefits

- Service and cost (questions 12, 14, and 15): 3 items related to professional capacity, product price, and number of repairs

- Negative factors (questions 2, 7, and 11): 3 items related to environmental noise amplification, acoustic feedback, and telephone use

- Personal image (questions 4, 8, and 13): 3 items related to aesthetics and the stigma of using hearing aids.

The 14 questions about satisfaction were answered on a 7-point scale of equal intervals corresponding to a categorical scale ranging from "not a bit" to "very much" satisfied. The score was calculated for each subscale, and higher scores represented better user perception of satisfaction.

To facilitate the subjects' understanding of the range of responses, a visual support type of scale was presented to each individual. This scale displayed representative figures for the 7 levels of responses (Figures 1 and 2).

The answers to the questions related to each subscale were averaged to generate a score for each of the 4 subscales. All subscales must have been scored for the

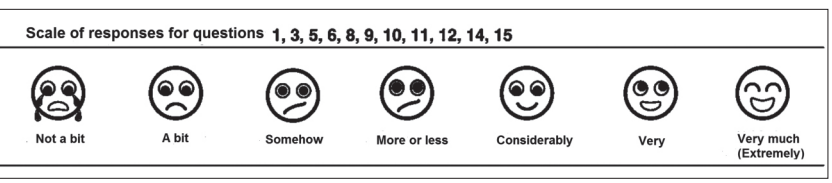

Figure 1. Scale of responses to questions $1,3,5,6,8,9,10$ $11,12,14$, and 15 . Visual support scale adapted to the scale of responses to the Satisfaction with Amplification in Daily life questionnaire (SADL) for questions with non-inverted scores.

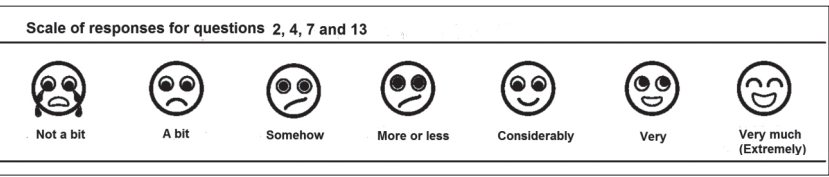

Figure 2. Scale of responses to questions 2, 4, 7, and 13. Visual support scale adapted to the scale of responses to the SADL for questions with inverted scores. 
score to be considered valid and used in the analysis. The 4 subscales of the SADL represent 4 different areas that contribute to the overall satisfaction. The overall satisfaction score was calculated as the mean of the subscale scores. The items are scored so that a high score represents high satisfaction.

Speech perception under quiet conditions was assessed by testing the recognition of separate lists of monosyllabic words, nonsense syllables, and sentences. The results were expressed as the percentage of correct answers.

Perception of speech in the presence of background noise was evaluated using a version of the Hearing in Noise Test (HINT) adapted to Brazilian Portuguese (2) under free field conditions, both in quiet and with background noise, using 2 lists (list 5 in the quiet and list 6 in the noisy environment) of 20 sentences each. We opted to use HINT under free field conditions due to the participants' use of CIs, which precluded the use of headphones.

The HINT results were expressed by Sentence Recognition Threshold (SRT/HINT) values. Under quiet conditions, this threshold corresponded to the intensity in decibels at which the individual exhibited 50\% sentence recognition; in the presence of background noise, this threshold corresponded to the $\mathrm{S} / \mathrm{R}$ ratio in decibels at which the individual exhibited $50 \%$ sentence recognition.

\section{Statistical Analysis:}

We performed a descriptive analysis of the results in order to characterize the subjects' responses..

The Spearman correlation test was also used to verify the correlations between the overall satisfaction level and each SADL subscale with the characteristics of the participants (e.g., duration of CI use) and the speech perception results under quiet and noisy conditions. A significance level of $5 \%$ was adopted.

\section{RESULTS}

The study comprised 12 adult users of CIs from the Audiological Research Center of the Hospital for Rehabilitation of Craniofacial Anomalies (HRAC/USP). No potential subject was excluded during the selection stage within the period determined for the study.

On average, the participants had undergone CI surgery at 36 years of age and had used their devices for 3 years (Table 1). Only 2 participants used hearing aids in the contralateral ear.
The participants in the study were on the whole satisfied with their devices and recorded high scores both overall and on the subscales of the SADL questionnaire (Table 2).

Examination of the results for speech perception under quiet and noisy conditions for correlations with the satisfaction scores revealed a correlation between the degree of satisfaction and the level of speech perception under quiet conditions (Table 3).

Only 6 (50\%) participants performed the HINT speech perception test under quiet conditions, and only 5 (41\%) performed it under noisy conditions (HINT) (Table 4). No correlation was found between the satisfaction scores and the HINT results (Table 5).

\section{DISCUSSION}

This study aimed to evaluate the degree of satisfaction of adult users of CIs and examine its relationship with their levels of speech perception.

The participants in the study were satisfied with their devices, and the degree of satisfaction correlated positively with the ability to recognize monosyllabic words under quiet conditions, that is, the better a person's performance on this test, the more satisfied the participant tended to be with his or her device. The duration of use of the device did not influence the satisfaction scores; this contrasts with the results of Tyler and Summerfield (16) (1996), who reported a correlation between the duration of use and satisfaction. It is noteworthy that those authors

Table I. Current age, age at surgery, and duration of cochlear implant $(\mathrm{Cl})$ use of the subjects.

\begin{tabular}{lcccc}
\hline & Mean & Median & Minimum & Maximum \\
\hline Age atsurgery(years) & 36 & 38 & 4 & 56 \\
Duration of Cl use (years) & 3 & 2 & 1 & 15 \\
Currentage(years) & 40 & 40 & 19 & 59 \\
\hline
\end{tabular}

Table 2. Subjects' $(\mathrm{n}=12 \mathrm{global}$ and 4 subscale scores on the Satisfaction with Amplification in Daily Life (SADL) subscales: mean, standard deviation (SD), median, maximum, and minimum values.

\begin{tabular}{|c|c|c|c|c|c|}
\hline SADL & Average & SD & Minimum & Maximum & Median \\
\hline Global & 4.8 & 1.3 & 2.5 & 6.2 & 5.1 \\
\hline Positive Effects & 4.9 & 1.6 & 1.5 & 6.8 & 5.4 \\
\hline Service and Cost & 5.5 & 1.9 & 1.0 & 7.0 & 6.5 \\
\hline Negative Factors & 3.6 & 1.4 & 1.5 & 6.0 & 3.7 \\
\hline Personal lmage & 4.9 & 1.3 & 3.0 & 6.7 & 4.7 \\
\hline
\end{tabular}


Table 3. Correlations between degrees of satisfaction (overall and each SADL subscale) and the participants' characteristics (duration of use of $\mathrm{Cl}$ ) and speech perception results.

\begin{tabular}{lcccccccc}
\hline & \multicolumn{2}{c}{ Duration of use of Cl } & \multicolumn{2}{c}{ Monosyllables } & \multicolumn{2}{c}{ Nonsense syllables } & \multicolumn{2}{c}{ Sentences } \\
& $p$ & $r$ & $p$ & $r$ & $p$ & $r$ & $p$ & $r$ \\
\hline Global & 0.9214 & -0.0320 & $0.0127 *$ & 0.6916 & 0.1079 & 0.4875 & 0.1356 & 0.4566 \\
Positive Effects & 0.9305 & 0.0283 & $0.0093 *$ & 0.7128 & 0.0723 & 0.5363 & 0.0501 & 0.5757 \\
Serviceand Cost & 0.3047 & -0.3237 & 0.3931 & 0.2716 & 0.5376 & 0.1979 & $0.559 \mid$ & 0.1877 \\
NegativeFactors & 0.4131 & 0.2607 & 0.4015 & 0.2670 & 0.9912 & 0.0036 & 0.7876 & 0.0872 \\
Personallmage & 0.7664 & -0.0961 & 0.0965 & 0.5018 & 0.2656 & 0.3494 & 0.5031 & 0.2145 \\
\hline
\end{tabular}

$* p<0.05=$ statistically significant

Table 4. Results obtained from Hearing in Noise Test(HINT) application under free field conditions, either in quiet or with background noise $\left(\mathrm{S} / \mathrm{R} 180^{\circ}\right)$.

\begin{tabular}{lcc}
\hline \multicolumn{2}{c}{$\begin{array}{c}\text { Distribution of Patients }(\mathrm{n}=12) \\
\text { HINT(Quiet) } \\
\end{array}$} & HINT $($ Noisy) \\
\hline Mean & 52.5 & $\left(\mathrm{~S} / \mathrm{R} / 80^{\circ}\right)(\mathrm{dB})$ \\
$\mathrm{SD}$ & 9.9 & $6.7 \mid$ \\
Median & 48.7 & 4.4 \\
Minimum & 46.3 & 7.4 \\
Maximum & 74.7 & 0.8 \\
\hline
\end{tabular}

Subtitle: SD, standard deviation.

used a different assessment of satisfaction than employed in the current study.

The mean scores on the SADL questionnaire were lower for this population than in the study conducted by Ou, et al. (12) (2008), who found an overall score of 5.6. Those authors used the SADL questionnaire to assess satisfaction among post-lingual users of CI, i.e., those who had established oral language before they developed hearing loss. Only 1 participant in our study had undergone the surgery during childhood and thus before the acquisition of oral language.

The highest score was recorded for the Service and Cost subscale, showing that CI users were satisfied with the services received and CI maintenance. The cost of the device is known to be able to impact user satisfaction, and in the case of CI, which are high-tech and costly devices, the need for a great deal of maintenance could also impact these results, as there is currently no federal guideline ensuring the repair and maintenance of such devices. Therefore, CI care should be emphasized throughout the therapeutic process.

The lowest score was recorded for the Negative Factors subscale, which was related to the amplification of background noise and telephone use. Despite the benefits that the CI confers on its user with respect to the perception
Table 5. Correlations between the SADL overall and subscale satisfaction levels and the HINT results under quiet and noisy conditions.

\begin{tabular}{lcccc}
\hline & \multicolumn{2}{c}{ HINT(Quiet) } & \multicolumn{2}{c}{ HINT(Noisy) } \\
& $p$ & $r$ & $p$ & $r$ \\
\hline Global & 0.7876 & 0.1261 & 0.8268 & 0.1160 \\
Positive Effects & 0.9694 & -0.0180 & 0.9131 & 0.0580 \\
Service and Cost & 0.6057 & 0.2390 & 0.3552 & 0.4629 \\
Negative Factors & 0.2103 & -0.5406 & 0.5379 & 0.3189 \\
Personal Image & 0.8463 & 0.0909 & 0.8679 & 0.0883 \\
\hline
\end{tabular}

$* p<0.05=$ statistically significant

of sound, recognition of speech in noisy environments remains a very challenging situation even for adults with implants (14). Studies have shown that the use of advanced technological systems associated with CIs can reduce the adverse effects of noisy environments (5). The systems currently available to minimize the effects of noise on the speech perception of CI users include new strategies for pre-processing, Frequency Modulation (FM) systems, directional microphones, and a larger input dynamic range (IDR) (14). Therefore, it can be anticipated that CI users will soon attain understanding of speech even in unfavorable communication situations, satisfactory musical perception, and effective communication on the telephone (8).

There are few studies in the literature concerning the perception of satisfaction among adult users of CI users, hampering the comparison of our findings with those of others. Zwolan, Kileny, and Telian (18) (1996) evaluated the satisfaction of 12 pre-lingual adult users of CI using a questionnaire that they had developed and found that satisfaction correlated more strongly with the perception of environmental sounds than with speech perception. Tateya, et al. (15) (2000) conducted a study of 37 CI users and found that speech understanding was one of the most important factors related to satisfaction. On the other hand, the level of satisfaction of CI users does not always correspond with the degree of improvement in their 
speech perception scores (9-15). Humes, Halling, and Coughlin (7) (1996) noted that speech perception scores correlate weakly overall with the benefit, satisfaction, or use of electronic devices.

Therefore, although better speech perception may be associated with greater user satisfaction, other factors also contribute to the perception of satisfaction (10), preventing us from predicting the degree of satisfaction based solely on the level of speech perception.

Some people may "be satisfied" with the CI without obtaining the maximumbenefit from it. This can be explained by the fact that different people use very different criteria to judge whether they "are satisfied" with their CI. At one extreme, some patients have unrealistic expectations of what the CI can do and hope that it will essentially eliminate the psychosocial, vocational, and communicative consequences of their hearing loss. Their satisfaction may depend on our success at reducing their expectations to a realistic level. In contrast, there are also patients who judge the success of the intervention process by comparing their comprehension skills with and without the CI. These are the individuals who can be satisfied with their devices even if the instrument they use provides less objective benefit than could possibly have been achieved. Furthermore, satisfaction is a dynamic rather than a static measure of intervention and may fluctuate over time (13).

Therefore, the assessment of satisfaction may help professionals to predict which other aspects in addition to speech perception may affect the satisfaction of CI users and reorganize the intervention process accordingly in order to improve patients' quality of life.

\section{CONCLUSION}

Overall, the participants were satisfied with their CI and the service received. The user's degree of satisfaction with the device correlated with the level of speech perception under quiet conditions.

\section{REFERENCES}

1. Bento RF, et al. Resultados auditivos com o implante coclear multicanal em pacientes submetidos a cirurgia no Hospital das Clínicas da Faculdade de Medicina da Universidade de São Paulo. Rev Bras Otorrinolaringol. 2004;70(5)632-7.

2. Bevilacqua MC, Banhara MR, Costa EA, Vignoly AB, Alvarenga KF. The Brazilian Portuguese Hearing In Noise Test (HINT). Int J Audiol. 2008, 47(6):364-365.
3. Carpenter RM. Correlates of sensorial hearing loss and their effects on hearing aid benefit and implications for cochlear implantation. In: Niparko JK. Cochlear Implants: principles \& Pratices. 2nd ed. Philadelphia: Lippincott Willians \& Wilkins; 2009. p. 83-93.

4. Cox RM, Alexander GC. Measuring satisfaction with amplification in daily life: The SADL Scale. Ear Hear. 1999;20(4):306-20.

5. Davidson LS, Geers AE, Blamey PJ, Tobey EA, Brenner CA. Factors contributing to speech perception scores in longterm pediatric cochlear implant users. Ear Hear. 2011;32(1):19-26.

6. Espiridião M,TradLAB. Avaliaçãode Satisfação de usuários. Ciência e Saúde Coletiva. 2005;10:303-12.

7. Humes LE, Halling D, Coughlin M. Reliability and stability of various hearing-aid outcome measures in a group of elderly hearing-aid wearers. J Speech Hear Res. 1996;39:923-35.

8. Krueger B, Joseph G, Rost U, Strauss-Schier A, Lenarz T, Buechner A. Performance groups in adult cochlear implant users: speech percep 7 tion results from 1984 until today. Otol Neurotol. 2008;29(4):509-12.

9. Lassaletta L, Castro A, Bastarrica M, de Sarria MJ, Gavilan J. Quality of life in postlingually deaf patients following cochlear implantation. Eur Arch Otorhinolaryngol. 2006;263:267-70.

10. Looi V, Mackenzie M, BirdP, Lawrenson R. Quality-oflife outcomes for adult cochlear implant recipients in New Zealand. N Z Med J. 2011;124(1340):21-34.

11. Mondelli MFC, Magalhães FF, Lauris JRP. Adaptação cultural do questionárioSADL (Satisfaction with Amplification in Daily Life) para o português brasileiro. Braz. J. otorhinolaryngol. 2011;77(5):563-72.

12. OuH, Dunn CC, Bentler RA, Zhang X. Measuring Cochlear Implant Satisfaction in Postlingually Deafened Adults with the SADL Inventory. J Am Acad Audiol. 2008;9:721-34.

13. Ross M. Consumer satisfaction is not enough; Hearing Aid still about hearing. Hearing Research. [Internet]. 2007 [cited 2012 Jul 5]. Available from: http:// www.hearingresearch.org/ross.htm

14. Tanamati LF, Bevilacqua MC, Costa OA. Cochlear implant in postlingual children: functional results 10 years after the surgery. BrazJ Otorhinolaryngol. 2012;78(2):10310 . 
15. Tateya T, Funabiki K, Naito Y, Fujiki N, Morita T. Factors influencing satisfaction of cochlear implant users-a questionnaire-based study. Nippon Jibiinkoka Gakkai Kaiho. 2000;103:1272-80.

16. Tyler RS, Summerfield AQ. Cochlear implantation: relationships with research on auditory deprivation and acclimatization. Ear Hear. 1996;17(38):523-39.
17. Yamamoto CH, Ferrari DV. Relação entre limiares audiométricos, handicap e tempo para procura de tratamento da deficiência auditiva. Rev Soc Bras Fonoaudiol. 2012;17(2):135-41.

18. Zwolan TA, Kileny PR, Telian SA. Self-report of cochlear implant use and satisfaction by prelingually deafened adults. Ear Hear. 1996;17:198-210. 